УДК 81 '42

DOI: 10.33184/YVDK-2021-04-30.11

\author{
А.Р. Рюкова (доц. БашГУ, г. Уфа), \\ Е.А. Филимонова (доц. БашГУ, г. Уфа)
}

\title{
НОВЫЕ СЛОВА В АНГЛИЙСКОМ ЯЗЫКЕ И ИХ ПЕРЕВОД НА РУССКИЙ
}

В статье рассматриваются новые слова, вошедшие в английский язык за последние несколько лет. Социальные факторы, политическая ситуачия в мире, технический прогресс, информационные технологии способствуют появлению новой лексики в языке. Новые слова в английском языке образуются путем сложения основ или их частей, образованием новых слов, в виде аббревиатуры, суффиксальным способом. $B$ статье приведены примеры использования новых слов в различных англоязычных СМИ.

Ключевые слова: новые слова, лексика, язык интернета, перевод.

The article considers new words which appeared in the English language during the last decades. Social factors, the political situation in the world, technical progress, information technologies contribute to the emergence of new lexical units in the language. The most popular ways of forming new words in English are blending, compound words, acronyms and sometimes suffixation.

Key words: new words, ways of forming new words, word formation, mass media.

«Английский язык является глобальным языком», занимая господствующее положение среди языков мира уже на протяжении более двухсот лет. Как справедливо отмечает британский филолог, языковед-англист Д. Кристал, язык становится международным, когда он начинает играть особую роль, признаваемую во всем мире. [D. Crystal 2003:24].

По различным статистическим данным [URL: https://englex.ru/english-in-numbers-and-facts/], четыреста миллионов человек являются носителями английского языка как 
родного, для семиста миллионов человек английский является первым иностранным языком, восемьдесят процентов международных конференций проходят на английском, девяносто процентов всей информации в интернете хранится на английском языке. Оксфордский словарь английского языка содержит приблизительно двести тысяч слов, и эта цифра постоянно увеличивается. Так, например, в марте 2021 года в Оксфордский словарь английского языка (Oxford Advanced Learner's Dictionary) было добавлено более девяносто новых слов.

Лексика является наиболее динамичным компонентом любого языка и обогащается во время значимых изменений в обществе. Значительна роль социальных факторов в развитии современного языка. Политическая свобода в обществе, техническое перевооружение быта, интернет и бурное развитие электронных СМИ приводят к обновлению языка.

Цель данной статьи рассмотреть новые слова, появившиеся в английском языке в двадцать первом веке под влиянием СМИ и всемирной сети интернет и способы их перевода на русский язык.

Язык интернета обладает характерными особенностями, отличающими его от языка других функциональных стилей, чем и вызывает огромный интерес исследователей. Язык электронных средств массовой информации в настоящее время также претерпевает изменения. Авторы статей газет и журналов, электронных ресурсов всячески пытаются привлечь внимание к предлагаемой информации, заинтересовать и развлечь.

Рассмотрим некоторые слова, появившиеся в английском языке за последнее десятилетия. Примеры взяты из электронного издания британской газеты The Guardian [[URL: https://www.theguardian.com/].

1. Слова, появившиеся путем слияния двух или нескольких основ или их частей.

Nomophobia - (no-mobile-phone-phobia) - fearing or worrying at the idea of being without your phone or unable to use it; номофобия, страх или беспокойство из-за невозможности использовать свой телефон:

You know the feeling - you have left your phone at home and feel anxious, as if you have lost your connection to the world. "Nomophobia" (short for no-mobile phobia) affects teenagers and 
adults alike Вам знакомо такое чувство, когда вы забыли телефон дома и обеспокоены, как будто вы потеряли связь с миром? «Номофобия» (сокращенно от фобия из-за отсутствия телефона) затрагивает как подростков, так и взросльх (здесь и далее перевод наш - A.P.).

Hangry - (hungry + angry) - feeling anger or irritability as a result of hunger; испытывающий злость или раздражение в результате голода:

The new rules of holiday eating: ditch TripAdvisor, embrace disaster, and make a plan for when you're 'hangry'.

Новые правила питания на отдыхе: пренебречь советами туристических сайтов, принять напасть и придумать план на случай, если разозлишься от голода.

To accidial - (to accidentally dial) - dial someone's number on phone accidentally; нечаянно набрать чужой номер:

The other day I accidialed my boss at 5 am, that was quite embarrassing.

На днях я нечаянно набрал моего босса в пять утра, было неловко.

Brexit - (Britain + exit) - a term that is used to denote the departure of the UK from the European Community; Брексит, термин, обозначающий выход Соединенного Королевства из ЕС:

The Jersey fishing standoff shows Brexit has only just begun.

Рыбацкое противостояние на Джерси показывает, что Брексит только начался.

Frenemy - (friend + enemy) - a person to whom one shows a friendly attitude despite a principal dislike; наполовину другнаполовину враг, отношения любви-ненависти:

From sisterly love to frenemies: the best female friendships in books.

От сестринской любви до заклятой ненависти: лучшие сиенарии женской дружбы в книгах.

Floordrobe - (floor + wardrobe) - an untidy pile of clothes that have been left on the floor; кипа вещей, оставленная на полу:

Clear up the 'floordrobe', throw away your conference freebies - and dump any clothes you wouldn't want your ex to see you in. 
Разбери кипу вещеей на полу, выброси все, что дали в подарок на распродажах - избавься от всего, в чем твой бывший не должен тебя видеть.

Kadult - (kid + adult) - person who is technically an adult due to age but still acts like a child; инфантильный молодой человек, ребенок:

You guys are such kadults. When are you going to grow up. That's why you don't have a girlfriend.

Ребята, вы такие дети. Когда вы собираетесь взрослеть? Поэтому, у вас нет девушек.

2. Сложные слова.

Awesomesauce (slang) - extremely good; excellent; отличный, классный, офигительный

Awesomesauce may sound like a ketchup business started by the dullest, most bored and married of your friends, but it's actually a cutesy way of saying something is great, that you like it].

«Офигительный» может звучать как производство кетчупа, начатое самым бестолковым, скучным женатым другом, однако, это остроумный способ сказать: что-то классное, и тебе нравится (в состав нового слова awesomesauce входит корень sauce, что означает соус; прим. переводчика).

Me time - the time a person devotes to themselves, to do something for their own pleasure ; личное время, период времени, который мы урываем, тратим только на себя:

Women and the guilt of 'me' time.

Женщины и вина личного времени.

Digital detox - a period of time when a person voluntarily refrains from using digital devices such as smartphones, computers, and social media platforms; цифровая детоксикация, время, проведенное без гаджетов, возможность уменьшить стресс и сосредоточиться на живом общении:

One of Britain's first "digital detox" companies is planning to expand its programmes to include teenagers as concern grows at the number of young people apparently unable to withdraw from the online world.

Одна из первых британских компаний по циифровой детоксикации планирует расширение своей программы по включению подростков, поскольку вызывает обеспокоенность 
количество молодых людей, неспособных выйти из виртуального мира.

Food baby - круглый торчащий живот от переедания:

It's probably just a food baby, didn't you have a big lunch?

Да у тебя живот просто раздулся, ты плотно пообедал?

3. Интернет аббревиатуры.

LMK - let me know; дай мне знать

WYCM - will you call me? Позвонишь мне?

PIR - parent in room; родитель в комнате

TWD - texting while driving; пишу сообщение за рулем

BBL - be back later; вернусь поздно

CTN - can't talk now; не могу сейчас говорить

GL - good luck; удачи

GTG - got to go; пора идти

JK - just kidding; шучу

YW - you're welcome; пожалуйста

[URL: $\quad$ https://www.webfx.com/internet-marketing/100-internetabbreviations-explained].

Интернет аббревиатуры обычно на русский язык не переводятся, уверенные пользователи умеют их употреблять даже без знания английского языка.

4. Суффиксальный способ.

Catastrophise - present a situation as worse than it is, imagine the worst possible outcome of an action or event : to think about a situation or event as being a catastrophe or having a potentially catastrophic outcome; представлять ситуацию в худшем свете чем она есть, усугублять, драматизировать:

"We can catastrophise goals too quickly," said Smith in December, after the home defeat by Southampton.

«Mы слишком быстро драматизируем по поводу голов», заявил Смит в декабре после поражения на своем поле в игре с Саутгемптоном.

Таким образом, рассмотрев некоторые слова, появившиеся в английском языке в двадцать первом веке и сделав попытку дать их перевод в контексте, отметим, что при переводе на русский язык целесообразнее использовать толкование слова, а не так называемые англицизмы. Однако, заимствования 
представляют собой естественный процесс изменения языка. Еще академик Яков Карлович Грот, выдающийся лингвист XIX века, утверждал, что «безусловная вражда к заимствованным словам не имеет разумного основания», а принятие чужих слов в язык «процесс естественный и неизбежный» [Грот 1873].

Возможно, со временем мы будем наблюдать тенденцию вхождения в русский язык новых англицизмов.

\section{ЛИТЕРАТУРА}

1. Грот Я.К. Филологические разыскания: Материалы для слов., грамматики и истории рус. яз. / [Соч.] Акад. Я. К. Грота. Санкт-Петербург: 2-е Отделение Акад. наук, 1873. - VIII, $668 \mathrm{c}$.

2. Инглекс.

[Электронный

pecypc].

URL: https://englex.ru/english-in-numbers-and-facts/ (Дата обращения 07.05.2021)

3. Crystal D. English as a Global Language. Second Edition. Cambridge University Press. 2003. - 212 pp.

4. Exam Word. [Электронный pecypc]. URL: https://www.examword.com/day/100-new-word-definitionsentence (Дата обращения 07.05.2021)

5. Language Systems. International College of English. [Электронный ресурc]. URL: http://idioms.languagesystems.edu/2018/09/kadult.html (Дата обращения 07.05.2021)

6. ReversoContext. [Электронный pecypc]. URL: https://context.reverso.net/ (Дата обращения 07.05.2021)

7. The Guardian. 2021 Guardian News and Media Limited or its affiliated companies. [Электронный pecypc]. URL: https://www.theguardian.com (Дата обращения 08.05.2021)

8. WebFX. [Электронный pecypc]. URL: https://www.webfx.com/internet-marketing/100-internetabbreviations-explained (Дата обращения 07.05.2021)

(C) Рюкова А.Р., Филимонова Е.А., 2021 г. 